\title{
Dentistry in our country
}

\author{
La odontología en nuestros días
}

Yolanda Valero Princet*

In recent times, population in our country has reached higher age average than in other times, in consequence, there is a rise in subjects aged 65 years and over. This new longevity has in turn brought about an increase in the number of patients afflicted by sickness or any other type of disabilities, as consequence of the natural deterioration caused by age. Dental problems caused by advanced age, obesity, HIV/Aids, resistance to antibiotics, tobacco addiction and alcoholism, are, among others, more frequent than in times gone by.

In the specific case of teeth, it is remarkable that most people do not consider the mouth as an important part of the body, since in fact, there are many toothrelated conditions. Many research projects highlight the close relationship existing between oral and general health. Some examples of this are pneumonic infections and periodontal and atherosclerotic diseases, as well as their consequences, such as premature deliveries, among others.

On the other hand, cosmetic and non-cosmetic dental treatments are in demand, not only from medically compromised patients, but also by healthy patients. This novelty places the oral health professional in the need to be cognizant of multiple medical conditions as critical part of his training. Only a thorough training in medical areas will provide us the possibility of offering high standards of oral health services. Continuous training is fundamental for a dentist, since he must count with needed preparation to recognize and prevent medical problems associated to dental treatment, so they can accurately refer patients to the suitable specialist, even more so since some, not to say almost all, arrive without a diagnosis. Other patients know about their disease but do not follow treatment, while others follow strict pharmacological regimes. The dentist's ability must allow him to identify symptoms in his patient, understand diagnosis and be aware of know pharmacological interactions between medical treatment and drugs used during dental treatment.
In an analogous manner, the dentist of the future must be sufficiently prepared to treat medical emergencies that might arise during dental consultations, and to treat cases that might appear in their work environment, stabilizing patients first and then referring them to medical services so as to receive final treatment.

All the aforementioned reveal the fact that training of new professionals in the oral health area is becoming very complex, since it is a discipline requiring wide scientific, technological knowledge and moreover, the dentist must count with extensive training in biomedical and basic sciences. Nevertheless, to acquire this profile will place him in a privileged place in his profession, and this will reap countless satisfactions for him.

It must be added that this is not only the case for general dentists, it also applies to specialists who have performed during many years, they must be equally be under constant training.

Finally, it is essential to underline that all dentists, either young or with many years of practice behind them, must base their practice on a thorough care of live tissues, great respect for life and above all, unbreakable ethical principles.

Mailing address:

Yolanda Valero Princet

E-mail: mvalero@uic.edu.mx

* Dean of the School of Dentistry. Intercontinental University.

(C) 2017 Universidad Nacional Autónoma de México, [Facultad de Odontologia]. This is an open access article under the CC BY-NC-ND license (http://creativecommons.org/licenses/by-nc-nd/4.0/).

This article can be read in its full version in the following page: http://www.medigraphic.com/facultadodontologiaunam 